\title{
Mind the gap: The role of mindfulness in adapting to increasing risk and climate change
}

\author{
Christine Wamsler ${ }^{1}$
}

Received: 11 August 2017 / Accepted: 14 December 2017 / Published online: 4 January 2018

(c) The Author(s) 2018. This article is an open access publication

\begin{abstract}
It is becoming clear that increasingly complex global challenges cannot simply be solved by new technology or governments alone. We also need to develop new social practices and encourage a broader cultural shift towards sustainability. Against this background, this paper explores the role of mindfulness in adapting to increasing risk and climate change. Based on a literature review, it assesses current research on 'mindful climate adaptation', and explores how individual mindfulness is linked to climate adaptation. While in practice mindfulness-based approaches to climate adaptation have gained widespread recognition (e.g., by the United Nations), the results show that related research is scarce and fragmented. There is almost no research into the role of mindfulness in climate adaptation. At the same time, new scientific domains are opening up in cognate fields that illuminate the mindfulness-adaptation nexus from certain perspectives. These fields include: (1) disaster management; (2) individual well-being; (3) organisational management; (4) environmental behaviour; (5) social justice; and (6) knowledge production. As new concepts and approaches emerge, they require critical construct validation and empirical testing. The importance of further investigation is supported by a complementary empirical study, which shows that individual mindfulness disposition coincides with increased motivation to take (or support) climate adaptation actions. The paper concludes that mindfulness has the potential to facilitate adaptation at all scales (through cognitive, managerial, structural, ontological, and epistemological change processes) and should, therefore, become a core element in climate and associated sustainability research. Finally, it sketches the conceptual trajectories of the mindfulness-adaptation nexus and presents a pioneering, comprehensive framework for 'mindful climate adaptation'.
\end{abstract}

Keywords Climate change - Inner transition - Inner transformation · Organisational mindfulness · Political mindfulness · Compassion · Sustainability · Well-being · Emotions · Urban governance $\cdot$ Planning $\cdot$ Risk reduction · Adaptation $\cdot$ Urban transformation $\cdot$ Traditional knowledge $\cdot$ Native knowledge $\cdot$ Mindful climate adaptation

\section{Introduction}

Climate change is creating increasingly complex sustainability challenges that require new pathways and innovation (Kates et al. 2001; Sol and Wals 2015). Climate variability, climate hazards, and disasters are a manifestation of a systemic world, characterized by multiple causations,

Handled by Akhilesh Surjan, Charles Darwin University, Darwin, Northern Territory, Australia.

Christine Wamsler

christine.wamsler@lucsus.lu.se

1 Lund University Centre for Sustainability Studies (LUCSUS), Lund University, Box 170, 22100 Lund, Sweden interactions, complex feedback loops, and inevitable uncertainty and unpredictability (Lang et al. 2012; IPCC 2014). However, current coordination mechanisms and problemsolving strategies appear insufficient to address these issues (Dhiman and Marques 2016; Kunze 2012; Sol and Wals 2015). At the same time, the potential influence of human beings' 'interiority' for impeding or supporting climate adaptation is increasingly recognised (O'Brian and Hochachka 2011; Moser 2008; Wamsler et al. 2017). New solutions need to be found.

Inner transition is emerging as a potential new pathway (Dhiman and Marques 2016; Esbjörn-Hargens 2009; Gidley 2007; Inglis 2008; Frawley 2006; Wamsler et al. 2017). 'Inner transition', as used here, describes change within individuals that relate to their (expanded) consciousness and is associated with changes in values and behaviour. It 
is supported by indigenous, religious, or spiritual practices, such as mindfulness.

Mindfulness is intentional, non-judgmental attentiveness to the present moment. This inherent capacity of the human organism is rooted in the fundamental activities of consciousness (Baer 2003; Condon et al. 2013; Kabat-Zinn 1990), and is linked to established theories of attention, awareness, and emotional intelligence (Buss 1980; Brown et al. 2007; Carroll 2016; Goleman 2011). It is often viewed as a pre-requisite to the development of compassion, and involves a fundamental shift in the way we think about, and ultimately act on, local and global economic, social, and ecological crises (Carroll 2016; Ericson et al. 2014; Scharmer 2009/2016).

Although there is an increasing awareness of the potential to address global sustainability and climate change through inner transition, related knowledge is scarce (Dhiman and Marques 2016; Daffara 2011; Hamilton 2008; Inayatullah 2005, 2011; Koger 2015; O'Brian and; Hochachka 2011; Sandercock and Senbel 2011; Wamsler et al. 2017; Ray and Anderson 2000; Woiwode 2016). This paper addresses the gap, and explores the role of mindfulness in climate adaptation to foster sustainability at multiple levels.

Based on a literature review (described in "Methodology"), this paper assesses current research on mindful climate adaptation and how individual mindfulness may be linked to climate adaptation (see "Results"). From this, the core conceptual trajectories of the mindfulness-adaptation nexus are outlined, constituting the first comprehensive framework for-what is called here- 'mindful climate adaptation' (see "Discussion and conclusions").

\section{Methodology}

The research method consisted of an in-depth qualitative literature review. The reviewed literature mainly consisted of scientific papers identified via Scopus, the Web of Science, LUBsearch, and Google Scholar. To ensure a comprehensive survey of relevant research across multiple disciplines, the search string included the following terms: (mindfulness OR mindful* OR contemplative OR compassion OR meditat*) AND ("climate change adaptation" OR (adaptation AND climate) OR "risk reduction" OR ("disaster response" OR "hazard response") OR ("disaster recovery" OR "hazard recovery") OR "hazard mitigation" OR names of specific hazards, such as flood OR storm OR landslide). This identified a considerable number of papers (e.g., 923 in Scopus on 11/05/2017). Irrelevant studies (false positives) were identified by screening the abstracts and removed. As the mindfulness-adaptation field is still emerging, there were a large number of false positives (e.g., only 132 out of the 923 Scopus articles were identified as potentially relevant). Other significant studies were identified using snowball sampling of the references until saturation was reached. The data analysis identified patterns in the mindfulness-adaptation nexus, related synergies, and research gaps. Literal reading and qualitative coding were used to analyse the results (Glaser and Strauss 1967; Strauss and Corbin 1998).

In parallel to this study, a quantitative survey was conducted that aimed to complement the literature review by empirically exploring how individual mindfulness is linked to climate adaptation. The survey study is presented in depth in Wamsler and Brink (2018). It took the form of a written questionnaire sent to 600 households in the coastal municipality of Lomma, in the Scania region of Sweden. This area was selected as it is expected to be one of the Swedish regions hardest hit by climate change (Hall et al. 2015; SCCV 2007). Households at risk from current and future climate change were identified based on municipal flood scenarios. The response rate was $36 \%(n=217)$. Individual mindfulness disposition was assessed by four questions, adapted from the Five-Facet Mindfulness Questionnaire (FFMQ) (Baer et al. 2006). The FFMQ is a 39-item standardised instrument based on a 5-point Likert scale that measures mindfulness across five dimensions: observing, non-reacting, non-judging, acting with awareness, and describing. The selected questions had been tested and adapted to Swedish audiences (FFMQ_SWE; Lilja 2009). Attitudes to climate adaptation were assessed by self-ratings and actual actions. For the former, respondents were asked to rate, on a 5-point Likert scale, how motivating they found nine different circumstances. For the latter, a quantitative measure of the level/diversity of actual activity was created from a checklist of 14 common household adaptation actions (Wamsler and Brink 2014a, b), and a free-text option. SPSS software was used to analyse the data, and calculate correlations (Spearman's rho) between mindfulness and the other variables. For more details, see Wamsler and Brink (2018).

\section{Results}

While, in general, mindfulness research is rapidly growing (AMRA 2016) with a 30\% annual increase (Ericson et al. 2014), this literature review shows a clear lack of scientific research on mindfulness in climate adaptation. At the same time, there are an increasing number of studies that address (often implicitly) fragments of the mindfulness-adaptation nexus. These were found at the interface between the cognate fields of: (1) disaster management; (2) individual wellbeing; (3) organisational management; (4) environmental behaviour; (5) social justice; and (6) knowledge production. They illuminate aspects of the mindfulness-adaptation nexus under different terms and concepts (Table 1) that relate to different phases and scales regarding the underlying 


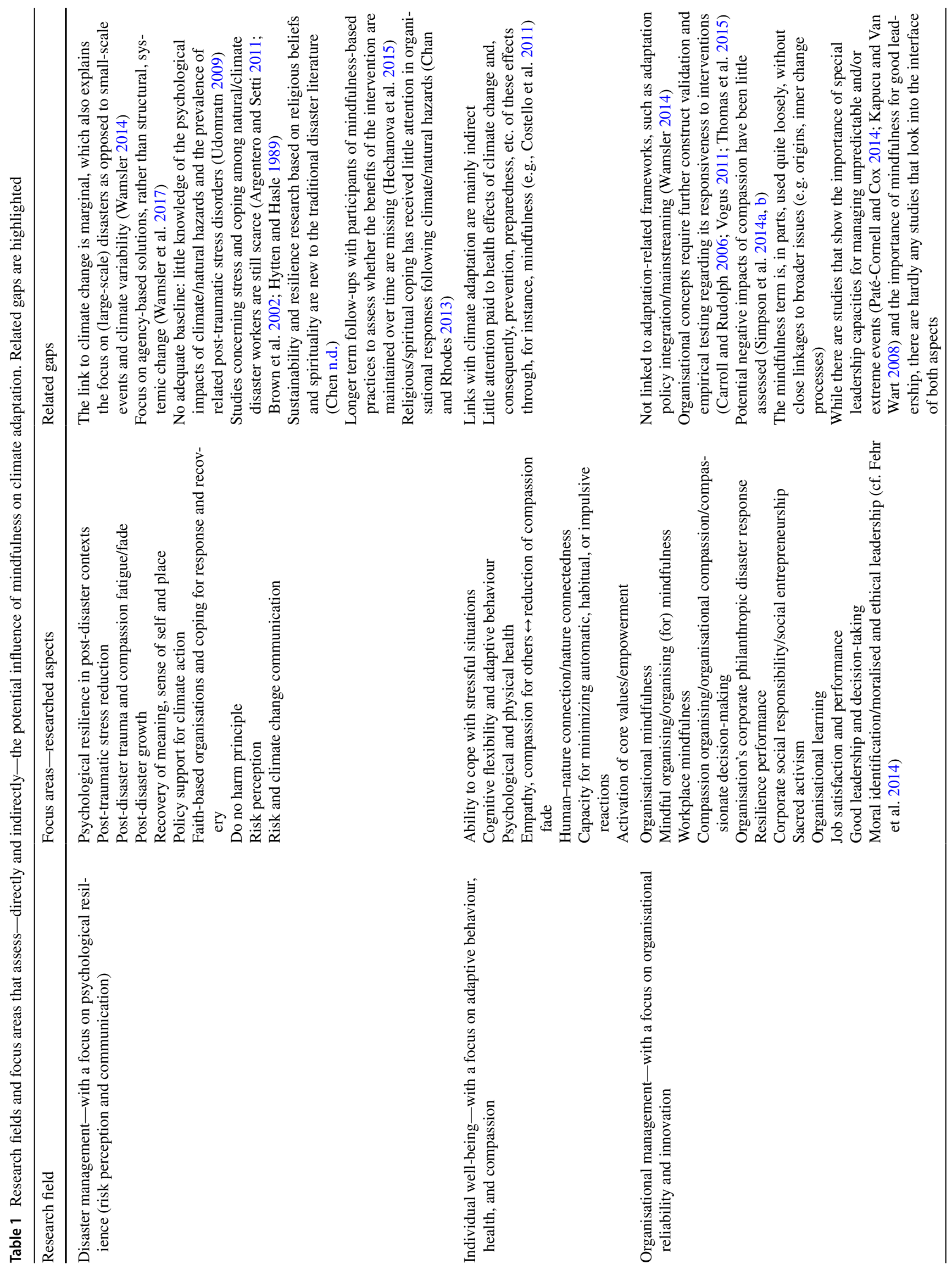


1124

Sustainability Science (2018) 13:1121-1135

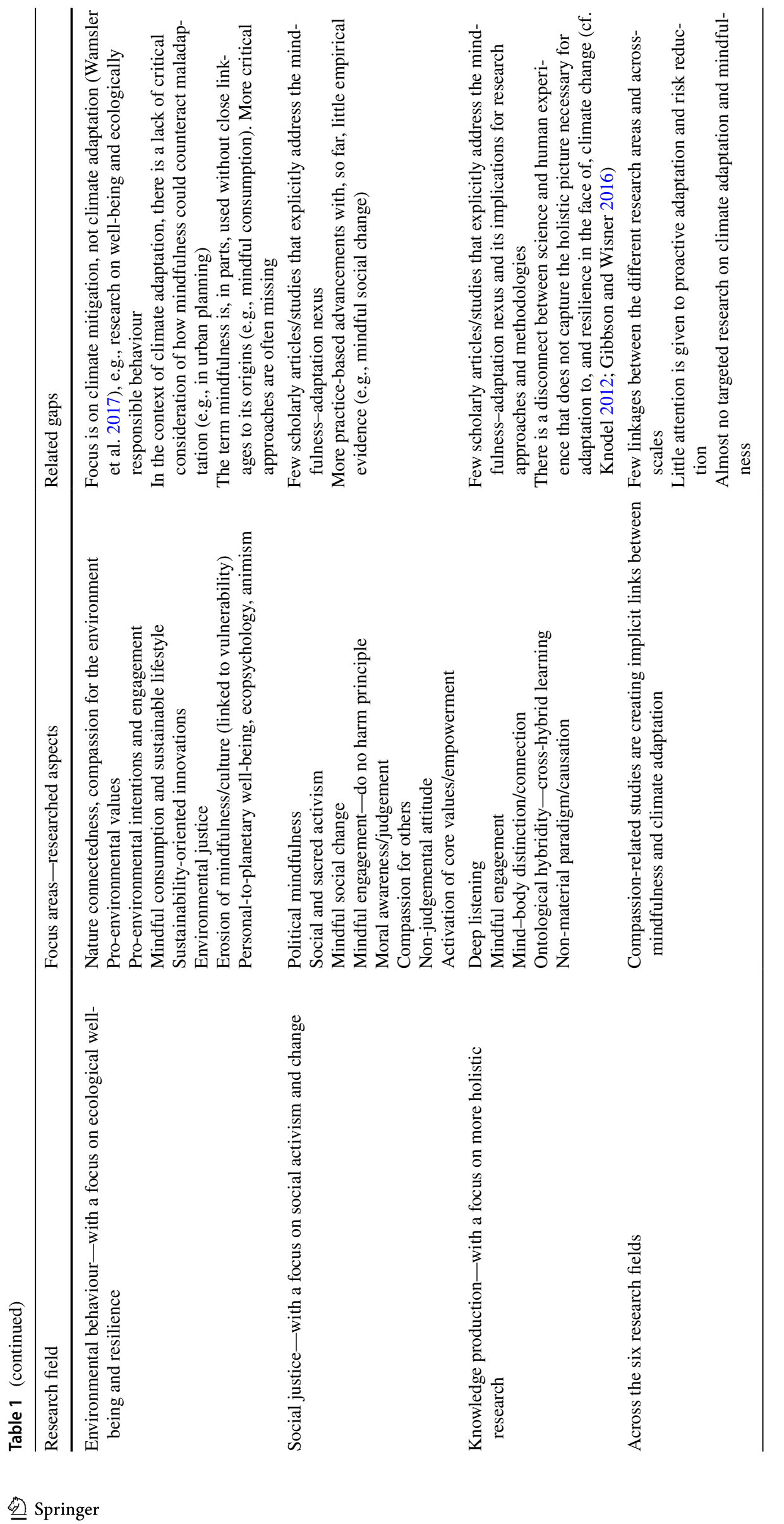


cognitive, managerial, collective, structural, ontological, and epistemological processes (Tables 1, 2, 3).

\section{Disaster management and well-being research}

The few studies that explicitly link mindfulness with climate adaptation mostly lie at the interface between well-being and disaster management research (Tables 1,2) with a focus on the post-disaster context (Table 2), and at an individual scale (Table 3). It is a growing body of research that illustrates the importance of mindfulness in post-disaster response and recovery to increase psychological resilience. Studies assess the potential importance of faith-based coping (Chen n.d.; Cherry and Allred 2012; Henslee et al. 2015; McGeehan 2012) and mindfulness interventions for different target groups: disaster victims, disaster aid workers (e.g., firefighters, healthcare professionals ${ }^{1}$ and volunteers), and disaster researchers (Catani et al. 2009; Hechanova et al. 2015; Hoeberichts 2012; Matanle 2011; Srivatsa et al. 2013; Yoshimura et al. 2015; Zeller et al. 2015; Eriksen and Ditrich 2015; Smith et al. 2011; Waelde et al. 2008; Setti and Argentero 2015, 2014; Abeni et al. 2014; Dierynck et al. 2017; Raab et al. 2015). They show the positive influence not only for reducing post-disaster trauma, post-traumatic stress disorder, ${ }^{2}$ and compassion fatigue, but also for supporting post-disaster growth (e.g., Chan and Rhodes 2013; Jacobsen 2008; Hanley et al. 2015; Shiyko et al. 2017). ${ }^{3}$ These beneficial effects of mindfulness and associated attributes are said to be related to its influence on well-being, in particular: (1) the ability to cope with stressful situations; (2) psychological/cognitive flexibility to adapt to new circumstances (Brown et al. 2007; Hechanova et al. 2015; Moore and Halinowski 2009; Waelde et al. 2008); (3) the capacity to minimize automatic, habitual, or impulsive reactions (Brown et al. 2007; Hechanova et al. 2015; Hülsheger et al. 2013; Waelde et al. 2008); (4) psychological and physical health in general (Black and Slavich 2016); (5) the activation of core values and compassion for others and the environment (Ericson et al. 2014; Howell et al. 2011, 2013; Lockhart 2011); and (6) the creation of a sense of self and place (Dueck and Byron 2011; Hanley et al. 2015; Roberto et al. 2010; cf.; Vandemark 2007) (Table 1).

\footnotetext{
1 Several reviews can be found on the potential of mindfulness-based approaches for health care professionals such as Irvin et al. (2009) and Raab (2014).

2 Post-traumatic stress disorder (PTSD) is an anxiety problem that may develop in some people after exposure to extremely traumatic events, such as climate hazards/disasters. Kim et al. (2013) review 16 publications and find that mind-body practices (including mindfulness-based practices) are associated with positive impacts on PTSD symptoms.

${ }^{3}$ See Collins and Long (2003) and Thompson et al. (2011) for related reviews.
}

While these capacities are clearly crucial in all phases and contexts of climate adaptation (Table 3), there are almost no studies of the interface between well-being and disaster management that address the issues of: (1) climate change; (2) mindfulness disposition; and (3) proactive adaptation, including response and recovery preparedness (Ryan 2016; Wamsler et al. 2017). ${ }^{4}$ The above-mentioned survey by Wamsler and Brink (2018) fills this gap by exploring how individual mindfulness is linked to climate adaptation. It complements the existing literature by showing that mindfulness disposition (as opposed to mindfulness interventions) might have positive impacts on response, recovery, and proactive climate adaptation. More specifically, a high mindfulness score was found to be positively correlated with a high score for overall motivation for climate adaptation, including both pro- and reactive actions (Wamsler and Brink 2018). In addition, while the number of adaptation actions taken was not correlated to individual mindfulness, a positive correlation was found between mindfulness disposition and one adaptation action, namely warning neighbours about a storm (Wamsler and Brink 2018). This aspect relates to another gap identified in the literature.

In fact, disaster management research that addresses the mindfulness-adaptation nexus has vastly overlooked issues of risk perception and risk communication, and how they translate into action-taking (Table 1). Only studies can be found that focus on certain attributes of mindfulness, such as emotions and compassion (e.g., Roeser 2012; Lu and Schuldt 2016; Smith and Leiserowitz 2014). Based on a diverse American sample, Lu and Schuldt (2016) show for instance that higher levels of compassion are consistent with a stronger belief that climate change is caused by human activities which, in turn, can mediate increased policy support. Positive emotions and compassion-based climate change communication have also been found to be more effective than 'motivation by fear' in the context of extreme weather and other climate phenomena (O'Neill and Nicholson-Cole 2009; Ryan 2016; Smith and Leiserowith 2014). In addition, Moser (2008) found that a sense of meaning beyond self-serving goals is essential in countering an individual's sense of isolation and futility vis-a-vis global warming. Nevertheless, many knowledge gaps remain (Coombs 2009; Roeser 2012; Lu and Schuldt 2016; Bohensky and Leitch 2014).

\section{Disaster management and organisational research}

The interface between disaster management and organisational research is another area that has addressed

\footnotetext{
4 An exception is Lyles (2015), who looks into the potential of applying 'compassion building programs' for sustainable planning in general, and risk reduction and adaptation planning in particular.
} 


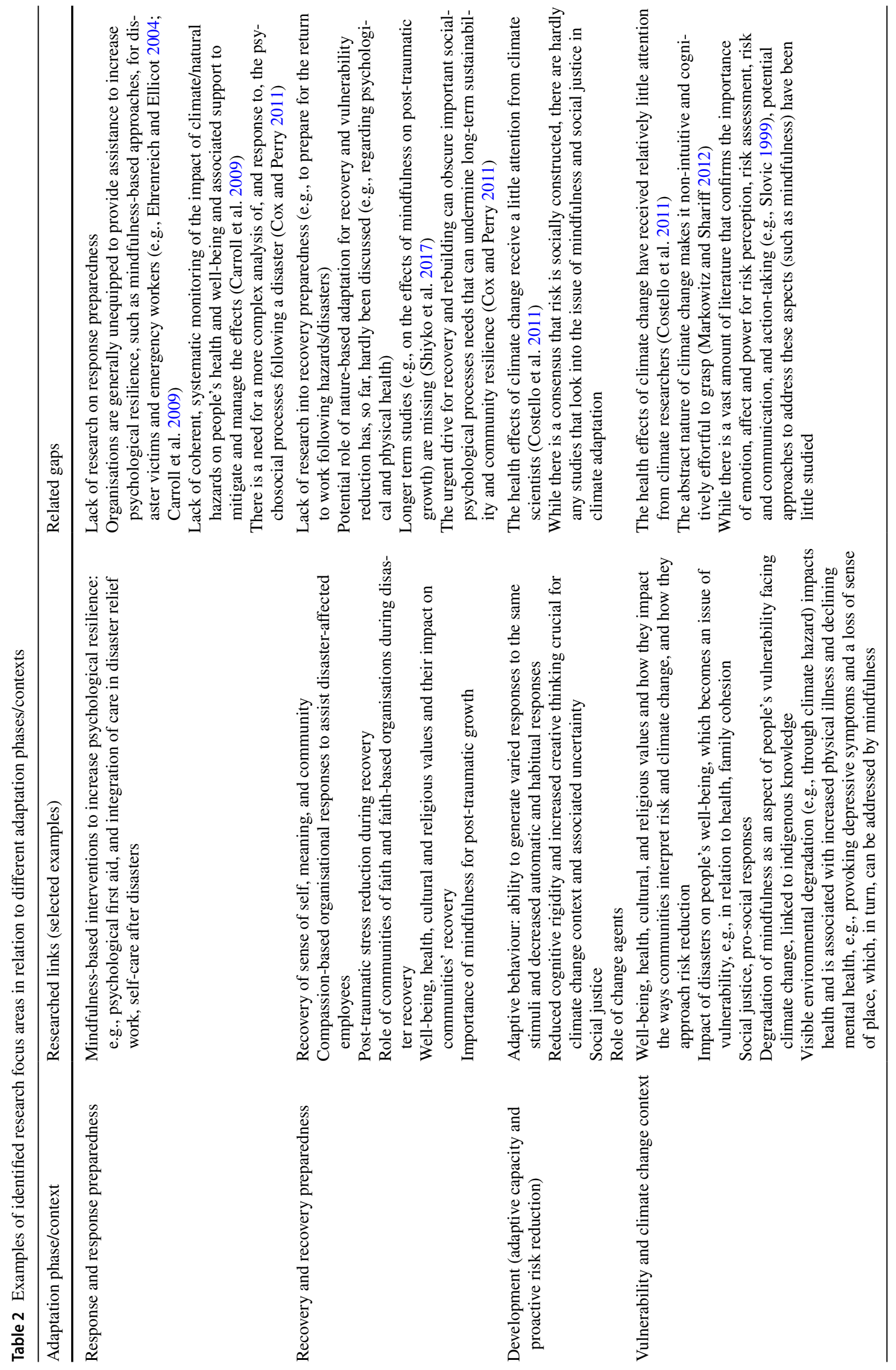


Table 3 Examples of research focus areas and their relation to different adaptation scales

\begin{tabular}{|c|c|c|}
\hline Scale & Researched links (selected example) & Related gaps \\
\hline Individual level & $\begin{array}{l}\text { Mindfulness may increase human potential, e.g., } \\
\text { through stress reduction and compassion }\end{array}$ & $\begin{array}{l}\text { Cognitive and agent-based focus of research with few } \\
\text { links to structural, systemic change } \\
\text { Few empirical studies and explicit links to climate } \\
\text { change and adaptation }\end{array}$ \\
\hline Organisational level & $\begin{array}{l}\text { Mindfulness may increase collective human potential, } \\
\text { e.g., through improved leadership, organisational } \\
\text { learning, and compassion for others within and } \\
\text { outside the organisation }\end{array}$ & $\begin{array}{l}\text { Studies focus on cognitive processes in high reliabil- } \\
\text { ity organizations and associated managerial aspects } \\
\text { within organisations, but a little enquiry into their } \\
\text { societal impacts and broader structural change (e.g., } \\
\text { through upscaling/mainstreaming) } \\
\text { Few explicit links to climate change and adaptation }\end{array}$ \\
\hline Societal level & $\begin{array}{l}\text { Mindfulness may increase action-taking for the com- } \\
\text { mon good, both individually and collectively }\end{array}$ & $\begin{array}{l}\text { In contrast to the individual and the organisational level, } \\
\text { there is hardly any research at the societal level } \\
\text { Related networks, scholarship etc. are just emerging/in } \\
\text { the making }\end{array}$ \\
\hline Science/research across levels & $\begin{array}{l}\text { Mindfulness-based approaches may support more } \\
\text { holistic research on disaster and climate risk reduc- } \\
\text { tion }\end{array}$ & $\begin{array}{l}\text { In contrast to the individual and the organisational level, } \\
\text { there is hardly any research that deals with epistemo- } \\
\text { logical and ontological questions }\end{array}$ \\
\hline
\end{tabular}

increasingly the mindfulness-adaptation nexus in recent years (Table 1; Levinthal and Rerup 2006). This is reflected in the emergence of concepts ${ }^{5}$ such as organisational mindfulness (Becke et al. 2012), mindful organising (Vogus 2011), organising (for) mindfulness (Thomas et al. 2015; Vogus 2011; Vogus and Sutcliffe 2012; Weick and Putnam 2006), workplace mindfulness (Dane and Brummel 2014), compassion organising (Duton et al. 2006; Shepherd and Williams 2014; Simpson et al. 2015), organisational compassion (Simpson et al. 2015); compasionate decisionmaking (Simpson et al. 2014a, b); resilience performance (Weick and Sutcliffe 2007), social entrepreneurship (Fernando 2007; Miller et al. 2012), corporate philanthropic disaster responses (May et al. 2015; Miller et al. 2012), and sacred activism (Pio and Syed 2014). These concepts describe individual and collective social and cognitive processes that increase a capability for awareness and support organisational learning and adaptability in a context of insecurity and uncertainty (Chiva and Habib 2015; Levinthal and Rerup 2006).

Organisational mindfulness emerged from the domain of risk and safety research, and has only recently been extended to climate adaptation (Aviles and Dent 2015; Becke 2014; Becke et al. 2012; Senghaas-Knobloch 2014). It describes behaviours of collective mindfulness in high reliability organisations (e.g., disaster management) that help in adapting to unexpected events (Weick et al. 1999). Organisational mindfulness is said to support collective and organisational learning with respect to the anticipation of, and coping

\footnotetext{
${ }^{5}$ Such concepts relate either directly to mindfulness or indirectly, in terms of compassion. Scholars define compassion in organisations as a threefold relational process of: collectively noticing that another is suffering, empathising with their pain, and responding.
}

with, unexpected events (Becke et al. 2012; Becke 2014), and to actively nurture the key social resources that underlie performance and sustainability when facing climate events with potentially long-lasting consequences (Becke 2014). It is based on the stated positive influence of mindfulness on overall well-being, understanding complexity, sensitivity to context and multiple perspectives, as well as cognitive flexibility and openness to novelty that, in turn, encourage organisations to constantly probe their environment for ways to stay ahead through innovation (Brown and Eisenhardt 1997; Greenberg et al. 2012; Colzato et al. 2012; Vogus and Welbourne 2003; Weick et al. 1999). In contrast, the notions of 'compassion organising' and 'corporate philanthropic disaster response' focus on how organisations relate to employees who have been affected by natural hazards (Simpson et al. 2015; Watkins et al. 2015; Thomas et al. 2015). Given the mounting evidence regarding differential vulnerability and the different impacts of hazards and associated responses, such approaches are becoming increasingly relevant for both organisational reliability and social equity (Hochwarter et al. 2008; Lilly et al. 2008).

Most of the organisational management concepts that address the mindfulness-adaptation nexus have only emerged in recent years, and empirical studies that provide evidence and practical guidance remain rare (Carroll and Rudoph 2006; Thomas et al. 2015; Table 1), ${ }^{6}$ especially in relation to climate adaptation. In addition, there is a lack of links between these concepts and organisational frameworks relevant to climate adaptation, such as adaptation policy integration and

\footnotetext{
${ }^{6}$ An exception is the development of games (and associated research) designed to improve compassionate responses developed by scholars and staff at the USAID Center for International Disaster Information (Özpolat et al. 2015).
} 
mainstreaming (Wamsler 2014). Another gap in the research is the lack of assessments of the potential negative impacts of mindfulness and compassion-based approaches in organisational management. As such approaches relate to complex social processes, embedded within power relations, outcomes are more likely to be ambivalent than wholly positive (Simpson et al. 2014a, b; Table 3).

This links to another area of organisational research relevant for exploring the mindfulness-adaptation nexus, namely leadership. In addition to the qualities that are traditionally associated with good leadership (vision, authority, etc.), mindfulness and associated emotional intelligence are increasingly seen as crucial (Goleman 1998, 2011). Studies have looked at the role of mindfulness (and mindlessness ${ }^{7}$ ) in good (bad) leadership and decision-making, as a component in leadership processes, as a leader attribute, and/or a human resource practice (Goleman 1998, 2011; Marques 2014; Vogus 2011; Vogus and Welbourne 2003). This is especially crucial in a context of climate change, where poor leadership has been shown to maximize hazard impacts, seen in the example of the Katrina-Rita hurricanes in New Orleans (Paté-Cornell and Cox 2014; Kapuco and Van Wart 2008), and where mindlessness has been associated with maladaptation, both in psychological and physical terms (Langer 1989). The survey results of Wamsler and Brink (2018) support the outcomes of this literature review in that they show that a high mindfulness score was found to be positively correlated with a high score for overall motivation to support or engage in adaptation. No further outcomes could be derived regarding organisational management, since the survey focused on at-risk-citizens, and not on climate professionals and/or organisations (Wamsler and Brink 2018).

\section{Environmental and well-being research}

In the domain of environmental research, fewer studies could be identified that make an explicit mindfulness-adaptation link (Table 1). Most environmental studies focus on objective interactions between natural, social, and human systems, while subjective, human, aspects tend to be ignored (Sumi 2007). However, it is a rapidly growing field. In fact, there is an increasing number of studies at the interface between environmental and well-being research that provide evidence for the potential influence of mindfulness on issues such as (1) human-nature connectedness (Amel et al. 2009; Anthony 2013; Howell et al. 2011; Lockhart 2011), (2) compassion for the environment

\footnotetext{
7 Brown and Ryan (2003) consider mindlessness as the relative absence of mindfulness, which, in simple terms, is found when individuals behave compulsively or automatically, without awareness of or attention to their behaviour (Deci and Ryan 1980).
}

(Pfattheicher et al. 2016; Bai 2013), (3) pro-environmental values (Ericson et al. 2014), (4) intentions and engagement (Amel et al. 2009; Brown and Kasser 2005; Jacob et al. 2009; Pfattheicher et al. 2016; Siqueira and Pitassi 2016), and (5) sustainability-oriented lifestyles and innovations (Amel et al. 2009; Brown and Kasser 2005; Brown and Ryan 2003; Brown et al. 2007, 2004; Ericson et al. 2014; Goleman 2009; Jacob et al. 2009; Sheth et al. 2010; Siqueira and Pitassi 2016; Lengyel 2015). Importantly, these aspects can assist in overcoming key psychological barriers that are said to limit climate adaptation, such as risk perceptions, anxiety, compassion fade, and ideological worldviews that preclude pro-environmental attitudes and behaviours (Gifford 2011; Markowitz et al. 2013; Moser 2008). Nevertheless, psychological aspects of climate change and adaptation have so far barely hit the radar of climate change science.

This situation has also given rise to the burgeoning ecopsychology movement. Ecopsychology can be seen as a psychological viewpoint of animism (Bai 2013; Reser and Bragg 2013). It seeks to understand ways to expand the emotional connection between individuals and the natural world and, ultimately, support more sustainable behaviour. Accordingly, it is interested in the knowledge provided by a wide variety of ancient and modern cultures that have a history of embracing nature, and its scholars argue that mindful awareness of our interdependence with nature not only helps us to regain our lost, ecologically embedded identity, but also helps us to behave more sustainably (Amel et al. 2009; Mayer and Frantz 2004; Roszak 1992; Roszak et al. 1995). This understanding is supported by an expanding body of scholarly evidence, suggesting that mindfulness is associated with environmentally responsible behaviour. It also led to the notion of 'ecological mindfulness', which was put forward in 2015 (Mueller and Greenwood 2015; Sol and Wals 2015). The survey by Wamsler and Brink (2018) supports this literature review in that a positive correlation was found between mindfulness and being a vegetarian.

The understanding that personal and planetary well-being are intrinsically interlinked (Koger 2015; Roszak et al. 1995; Jacob et al. 2009; Brown and Kasser 2005) is also in line with deep ecology's contention. It says that humankind requires a fundamental shift in consciousness to ensure ecological sustainability, and that the subject/object dualism inherent in Western empiricism and materialism will need to be transcended by meditative approaches such as mindfulness (Brinkerhoff and Jacob 1999). This resonates with the mindfulness principle of dependent origination (interdependence and interpenetration), which recognises that all beings are deeply connected to other beings and the world, including their actions and thinking (Yeh 2006; Bai 2013).

Most studies at the interface between environmental and well-being research address the mindfulness-adaptation 
nexus implicitly, for instance by focusing on compassion, an attribute of mindfulness (Table 1). They show that compassion can be positively correlated with pro-environmental values and behaviours that can translate into increased policy support, for example, in the form of donations to environmental organisations (Dickinson et al. 2016; Pfattheicher et al. 2016). At the same time, compassion fade has been found to be negatively correlated with pro-environmental values and behaviours, which may challenge the collective ability and willingness to confront major environmental problems (Markowitz et al. 2013). Compassion fade is said to reduce environmental identity, and is a significant psychological barrier to building broad public support for addressing environmental problems such as climate change (Markowitz et al. 2013).

\section{Environmental and social justice research}

Social justice is another relevant field for exploring the mindfulness-adaptation nexus (Table 1). Climate change has environmental and health consequences that disproportionately affect low-income countries and poor people in high-income countries, who must be protected (Levy and Platz 2015; Costello et al. 2011). It threatens civil and political rights, including the right to life, access to safe food and water, health, security, shelter, and culture (Levy and Platz 2015). Naturally, climate adaptation has become an issue of equity and social justice.

Mindfulness is said to politically sensitize people and organisations to the consequences of unquestioned structures and power relations at all scales (Dayley 2017; Senghaas-Knobloch 2014; Rowe 2017; Wamsler et al. 2017). It implies awareness and sensitivity to context, the cultivation of compassion, and intrinsic core values which, in turn, are assumed to be reflected in actions for the common good (Brown and Kasser 2005; Ericsson et al. 2014; Hanh and Weisman 2008; Kaza 2008). Accordingly, mindfulness does not simply address cognitions and cognitive schemes, but also fosters a sense of appropriate, or just, behaviour (Dayley 2017; Dhiman and Marques 2016; Senghaas-Knobloch 2012; Wamsler et al. 2017). However, associated empirical research has focused mainly on issues such as pedagogy (e.g., the integration of mindfulness into anti-oppressive pedagogy) and social work (e.g., the integration of mindfulness into social justice approaches into social work) (Berlila 2016; Hick and Furlotte 2009), not on climate adaptation.

Research into the interface between mindfulness and social justice in a context of climate change remains rare. However, it is becoming the focus of current mindfulness debates (Davis and Kabat-Zinn 2015) and a range of new concepts, such as political mindfulness (Rowe 2017; Senghaas-Knowbloch 2012, 2014), sacred activism (Pio and Syed 2014), mindful engagement (Wood and Mazur 2016), mindful social change ${ }^{8}$, and associated studies of moral awareness and judgement (Markowitz and Shariff 2012; Senghaas-Knowbloch 2012) are emerging. 'Political mindfulness' is closely related to organisational mindfulness (Table 1), but with a focus on the broader political community that sets the norms and rules for societal development, e.g., inter- and transnational organisations such as the World Bank (Senghaas-Knowbloch 2012). In contrast, sacred activism takes a bottom-up approach. A sacred activist can be described as someone who intentionally works towards social change, by providing compassionate services for others in the face of growing injustice, suffering, and violence, based on the perception that the world is experiencing a profound crisis and everyone needs to act (Harvey 2009; Pio and Syed 2014). Sacred activism is also closely linked to organisational research, as it is understood to be intertwined into a practical and pragmatic drive to transform institutions (Pio and Syed 2014). Similarly, 'mindful engagement' and 'mindful social change' concepts are emerging. Mindful engagement looks at collective social and environmental responsibility, based on the humanitarian principle of 'do no harm' (Anderson 1999; IFRC 2011; Wood and Mazur 2016). Mindful social change aims to explore the connection between mindfulness and transformative social change (Gonzáles 2017). However, here again, scholarly research is scarce and almost non-existent in relation to climate adaptation.

The complementary survey by Wamsler and Brink (2018) adds to this literature review in that it shows linkages between mindfulness and 'other-focused' social factors. More specifically, it showed a positive correlation between individual mindfulness and being motivated by social factors (i.e., encouraged by friends and family, reducing the risk for others, and having a 'good conscience'), while economic and ecological motivation could not be linked to mindfulness (Wamsler and Brink 2018). This outcome can be linked with social equity and justice. In addition, while the number of adaptation actions taken was not correlated to mindfulness disposition, a positive correlation was found between mindfulness disposition and one 'other-focused' adaptation action, namely warning neighbours about a storm (Wamsler and Brink 2018).

\section{Knowledge production}

Finally, there is one other emerging body of research that addresses the mindfulness-adaptation nexus, namely knowledge production. This can be seen as a reaction to the increasing recognition of a disconnect between human experience and scientific activity that does not capture a holistic

\footnotetext{
8 This new field is manifested in the creation of professional networks (e.g. the Mindfulness Initiative and its Mindfulness and Social Change Network, established in 2014), and academic journals (e.g. the Journal of applied thought leadership in operation, process improvement, people development, and mindful social change).
} 
picture of climate adaptation, risk reduction, and resilience for instance (Bai 2013; Gibson and Wisner 2016; Knodel $2012,2014)$. Science has always been shaped by contemporary problems, and it evolves with them. Until now, science research has been dominated by reductionism, as the intellectual and social model (Bai 2013). However, successful, it has been in the past, emerging policy issues and research into neuroplasticity, emotions and mindfulness seem to suggest that this ideal of rationality is no longer appropriate (cf. Schwartz 2011; Wamsler et al. 2017). Accordingly, risk and climate scholars are increasingly calling for research that incorporates local knowledge, i.e., ways of being, thinking, and knowing that are informed by centuries of lived experience and culture, and an approach that involves deep listening and joint internal reflection through external engagement (Gibson and Wisner 2016; Knodel 2012, 2014). This understanding is consistent with ecopsychology, animism, ecological mindfulness (Table 1), and associated interdisciplinary and cross-hybrid learning (Chinn 2015; Mueller and Greenwood 2015; Sol and Wals 2015). The latter states that knowledge production requires spaces where different perspectives can take root, be nurtured, and flourish into ways of knowing, being, and becoming that serve people, places, and the planet (Greenwood 2013; Gugerli-Dolder and Frischknecht-Tobler 2011; Sameshima and Greenwood 2015). It requires more expansive and inclusive approaches where researchers are free to take risks-risks that cannot be taken when academic fiefdoms determine the questions that are asked and regulate methodologies, rather than encourage new thinking and creativity (Mueller and Greenwood 2015). Such an understanding also resonates with recent feminist and cultural geography literature that speaks of emotion as an element in choosing research questions, and a driver of how research is conducted (Davidson et al. 2012; Sharp 2009).

However, only few studies have actually attempted to develop better approaches to knowledge production regarding risk and adaptation. An exception is the Frontline method, developed by the Global Network of Civil Society Organisations for Disaster Reduction (GNDR) (Gibson and Wisner 2016). This is based on mindfulness approaches such as deep listening (Hanh and Weisman 2008). This kind of 'listening' goes beyond the linguistic (i.e., language) and the cognitive (i.e., the application of frameworks derived from theories), and refers to opening up emotionally to an interlocutor, acknowledging one's emotional reaction to the situation one is studying, and allowing a transformational process of internal reflection through external engagement (Knodel 2012, 2014; Gibson and Wisner 2016; Wisner 2015).

Overall, the mindfulness-adaptation nexus raises questions about epistemological and ontological frameworks, the materialist paradigm that has shaped the construction of knowledge, in general, and climate science, in particular (cf. Bai 2013; Osborne and Grant-Smith 2015; Schwartz
2011; Schwartz et al. 2005; Wamsler et al. 2017). Some scholars argue that the current mind-body distinction itself may represent a premature cognitive commitment (Langer 1989), which requires that non-material causation need to be recognised as part of scientific inquiries (Bai 2013; Wamsler et al. 2017; Schwartz 2011; Schwartz et al. 2005). Here, this also means exploring the issue of mindfulness in climate adaptation, despite resistance and scepticism from scholars who dismiss the importance of critically looking at sustainability from an angle that is very different to the classical, large-scale, political, or institutional perspective.

\section{Discussion and conclusions}

The increasing numbers of disasters and climate change mean that humanity is facing ever more complex challenges (Kates et al. 2001; Sol and Wals 2015). However, the current approaches appear insufficient to address them (Kunze 2012; Sol and Wals 2015). New narratives and social practices are called for that encourage a broader, cultural shift towards sustainability (Dhiman and Marques 2016; Esbjörn-Hargens 2009; Gidley 2007; Inglis 2008; Frawley 2006; Wamsler et al. 2017). This study shows that mindfulness has the potential to support such a shift. While current knowledge on mindfulness in climate adaptation remains scarce and fragmented (cf. Tables 1, 2,3), it is gaining increasing momentum. Nearly all the relevant literature has been published in the past 5-10 years.

Mindfulness and adaptation are more connected than is generally thought. Based on an in-depth literature review, this study shows that mindfulness has the potential to contribute to facilitating climate adaptation at all scales, from the individual to the institutional and societal level. It may increase individual and collective capacity to deal with increasing risk and uncertainty-through cognitive, emotional, managerial, structural, ontological, and epistemological change processes. However, many research gaps remain (cf. Tables 1, 2, 3).

The analysis of the mindfulness-adaptation nexus resulted in the identification of several core conceptual trajectories for mindful climate adaptation (Tables 1,2,3); they imply the critical consideration of mindfulness in supporting:

1. Private ${ }^{9}$ adaptation: for instance, by reducing vulnerability (e.g., psychological and physical well-being, and risk

\footnotetext{
9 'Private adaptation' refers to initiatives taken by individuals or private households, rather than authorities or governments, and corresponds to 'autonomous adaptation'. Both private/individual and public adaptation can be a conscious or unconscious response to actual or expected climate change, including variability and extremes (IPCC 2001, 2014; Malik et al. 2010).
} 
perception), improving post-disaster response, recovery, and growth (e.g., the ability to cope with stressful situations), and increasing motivation and action-taking for reducing risk (e.g., clarification of values, increased empathy and compassion, adaptive capacity, and environmental behaviours).

2. Public-private adaptation and governance: for instance, by improving climate change communication, climate policy support, and new social approaches, norms, and values that challenge the business-and-power-as-usual norm. Mindfulness can thus be seen as another pillar in institutional attempts to support transformation, which can complement other angles. Criticism of existing institutions and power relations as drivers of vulnerability and risk thus also need to be extended to include a critique of these institutions as inflexible, unimaginative, and emotionally dead [classically seen as the characteristics of bureaucracy (Fesler 1965)].

3. Adaptation policy integration and mainstreaming: for instance, by influencing organisational reliability (organisational learning and innovation), nurturing social capital (good leadership and staff support), providing an ethical grounding, and a legitimate basis to negotiate adaptation objectives across cultures and inspire better practices (compassion for others, social activism, equity, and justice).

4. Adaptation science: for instance, by shaping new research questions, methodologies (deep listening, cross-hybrid learning, non-material causations) and, ultimately, knowledge production. This requires the incorporation of local knowledge, acknowledging and respecting humanity (including citizens, bureaucrats and even corrupt leaders), possibly leading to dialogue and positive change. ${ }^{10}$

Finally, in terms of the four dimensions that are identified, mindful climate adaptation also implies: (1) the critical consideration of their interdependence (e.g., individual and planetary well-being and adaptation), and (2) a detailed evaluation of potential drawbacks (Doran 2017; Walsh 2016). While this study did not find any structural critiques of mindfulness for climate adaptation, potential side-effects (Howard 2016), the inappropriate use of techniques (Williams and Kabat-Zinn 2011; Purser and Loy 2013), and the potential co-optation of mindfulness for capitalist purposes (Carrette and King 2005) have to be considered. In addition, further research is needed to critically look into context and pre- or co-conditions that can support individual mindfulness to bring about societal transformation. This sudy concludes that mindfulness has

10 This implication is especially relevant for those who support criticisms of the political ecology (cf. Wisner 2015). the potential to foster climate adaptation at multiple levels, from individual to global, and calls for further critical research into how we can tap into this potential to drive global change.

Open Access This article is distributed under the terms of the Creative Commons Attribution 4.0 International License (http://creativecommons.org/licenses/by/4.0/), which permits unrestricted use, distribution, and reproduction in any medium, provided you give appropriate credit to the original author(s) and the source, provide a link to the Creative Commons license, and indicate if changes were made.

\section{References}

Abeni MS, Magni M, Conte M, Mangiacavalli S, Pochintesta L, Vicenzi G, Ferretti VV, Pompa A, Cocito F, Klersy C, Corso A (2014) Psychological care of caregivers, nurses and physicians: a study of a new approach. Cancer Med 3(1):101-110

Amel EL, Manning CM, Scott BA (2009) Mindfulness and sustainable behavior: pondering attention and awareness as means for increasing green behavior. Ecopsychology 1(1):14-25

AMRA (2016) Database of the American Mindfulness Research Association (AMRA). https://goamra.org/resources/. Accessed 21 May 2017

Anderson MB (1999) Do no harm: how aid can support peace or war Lynne Rienner Publishers, Boulder, Colorado, USA, p 161

Anthony R (2013) Animistic pragmatism and native ways of knowing: adaptive strategies for overcoming the struggle for food in the sub-Arctic. Int J Circumpolar Health 72:1-7

Argentero P, Setti I (2011) Engagement and vicarious traumatization in rescue workers. Int Arch Occup Environ Health 84:67-75

Aviles PR, Dent EB (2015) The role of mindfulness in leading organizational transformation: a systematic review. J Organ Change Manag 20(3):31-55

Baer RA (2003) Mindfulness training as a clinical intervention: a conceptual and empirical review. Clin Psychol Sci Pract 10(2):125-143

Baer RA, Smith GT, Hopkins J, Krietemeyer J, Toney L (2006) Using self-report assessment methods to explore facets of mindfulness. Assessment 13:27-45

Bai H (2013) Peace with the earth: animism and contemplative ways. Cult Stud Sci Educ 10(1):135-147

Becke G (2014) Mindful change in times of permanent reorganization, CSR, sustainability, ethics and governance. Springer, Berlin

Becke G, Behrens M, Bleses P, Meyerhuber S, Senghaas-Knobloch E (2012) Organizational and political mindfulness as approaches to promote social sustainability. artec paper $\mathrm{Nr} .183$, artec Forschungszentrum Nachhaltigkeit. Universität Bremen, Germany

Berila B (2016) Integrating mindfulness into anti-oppression pedagogy: social justice in Higher education. Routledge, New York

Black DS, Slavich GM (2016) Mindfulness meditation and the immune system: a systematic review of randomized controlled trials. Ann N Y Acad Sci 1317(1):13-24

Bohensky EL, Leitch AM (2014) Framing the flood: a media analysis of themes of resilience in the 2011 Brisbane flood. Reg Environ Change 14(2):475-488

Brinkerhoff M, Jacob J (1999) Mindfulness and quasi-religious meaning systems: an empirical exploration within the context of ecological sustainability and deep ecology. J Sci Study Relig 38:524-543 
Brown SL, Eisenhardt KM (1997) The art of continuous change: linking complexity theory and time-paced evolution in relentlessly shifting organizations. Adm Sci Q 42(1):1-34

Brown KW, Kasser T (2005) Are psychological and ecological wellbeing compatible? The role of values, mindfulness, and lifestyle. Soc Indic Res 74(2):349-368

Brown KW, Ryan RM (2003) The benefits of being present: mindfulness and its role in psychological well-being. J Personal Soc Psychol 84:822-848

Brown J, Mulhern G, Joseph S (2002) Incident-related stressors, locus of control, coping, and psychological distress among firefighters in Northern Ireland. J Trauma Stress 15:161-168

Brown KW, Kasser T, Ryan RM, Konow J (2004) Having and being: investigating the pathways from materialism and mindfulness to well-being. University of Rochester, New York, USA (Unpublished data)

Brown KW, Ryan RM, Creswell JD (2007) Mindfulness: theoretical foundations and evidence for its salutary effects. Psychol Inq 18(4):211-237

Buss AH (1980) Self-consciousness and social anxiety. Freeman, San Francisco

Carrette J, King R (2005) Selling spirituality: the silent takeover of religion. Routledge, London

Carroll J (2016) Formless meditation and sustainability. In: Dhiman S, Marques J (eds) Spirituality and sustainability: new horizons and exemplary approaches. Springer, Switzerland

Carroll JS, Rudolph JW (2006) Design of high reliability organizations in healthcare. Qual Saf Health Care 15(suppl:I):i4-i9

Carroll B, Morbey H, Balogh R, Araoz G (2009) Flooded homes, broken bonds, the meaning of home, psychological processes and their impact on psychological health in a disaster. Health Place 15(2):540-547

Catani C, Kohiladev M, Ruf M, Schauer E, Elbert T, Neuner F (2009) Treating children traumatized by war and Tsunami: a comparison between exposure therapy and meditation-relaxation in North-East Sri Lanka. BMC Psychiatry 9(1):1-11

Chan CS, Rhodes JE (2013) Religious coping, posttraumatic stress, psychological distress, and posttraumatic growth among female survivors four years after Hurricane Katrina. J Trauma Stress 26(2):257-265

Chen TYS (n.d.) A Buddhist approach to disaster recovery and resilience in Sri Lanka. PhD Candidate, Faculty of Architecture, Building and Planning University of Melbourne. http://www. iiirr.ucalgary.ca/files/iiirr/52.pdf

Cherry SM, Allred K (2012) Models of disaster response: Lessons learned from Filipino immigrant mobilizations for Hurricane Katrina evacuees. Crim Justice Stud 25(4):391-408

Chinn PWU (2015) Place and culture-based professional development: cross-hybrid learning and the construction of ecological mindfulness. Cult Stud Sci Educ 10:121-134

Chiva RA, Habib JB (2015) A framework for organizational learning: zero, adaptive and generative learning. J Manag Organ 21(3):350-368

Collins S, Long A (2003) Working with the psychological effects of trauma: consequences for mental health-care workers-a literature review. J Psychiatr Ment Health Nurs 10(4):417-424

Colzato LS, Ozturk A, Hommel B (2012) Meditate to create: the impact of focused-attention and open-monitoring training on convergent and divergent thinking. Front Psychol 3:116

Condon P, Desbordes G, Miller W, DeSteno D (2013) Meditation increases compassionate responses to suffering. Psychol Sci 24(10):2125-2127

Coombs WT (2009) Information and compassion in crisis responses: a test of their effects. J Public Relat Res 11(2):125-142

Costello A, Maslin M, Montgomery H, Johnson AM, Ekins P (2011) Global health and climate change: moving from denial and catastrophic fatalism to positive action. Philos Trans R Soc Lond A Math Phys Eng Sci 369:1866-1882

Cox R, Perry KM (2011) Like a fish out of water: Reconsidering disaster recovery and the role of place and social capital in community disaster resilience. Am J Community Psychol 38:395-411

Daffara P (2011) Rethinking tomorrow's cities: emerging issues on city foresight. Futures 43:680-689

Dane E, Brummel BJ (2014) Examining workplace mindfulness and its relation to job performance and turnover intention. Hum Relat 67:105-128

Davidson J, Smith MM, Bondi L (2012) Emotional geography. Ashgate, Farnham

Davis A, Kabat-Zinn J (2015) How can we bring mindfulness to social justice movements? EBMC Benefit. Scottish Rite Temple. https:// www.youtube.com/watch? $\mathrm{v}=\mathrm{rbiM}-\mathrm{vH} 83$ YQ\&list=PLGP57y64pOTYAjGjZda-F0Dr-8tpKTpY

Dayley G (ed) (2017) The arrow: a journal of wakeful society, culture and politics. Special issue on Contemplative empowerment and social change, vol 4(2), pp 1-92

Deci EL, Ryan RM (1980) Self-determination theory: when mind mediates behavior. J Mind Behav 1:33-43

Dhiman S, Marques J (eds) (2016) Spirituality and sustainability: new horizons and exemplary approaches. Springer, Switzerland

Dickinson JL, McLeod P, Bloomfield R, Allred S (2016) Which moral foundations predict willingness to make lifestyle changes to avert climate change in the USA? PLoS One 11(10):e0163852

Dierynck B, Leroy H, Savage GT, Choi E (2017) The role of individual and collective mindfulness in promoting occupational safety in health care. Med Care Res Rev 74(1):79-96

Doran P (2017) A political economy of attention, mindfulness and consumerism: reclaiming the mindful commons. Routledge, New York

Dueck A, Byron K (2011) Community, spiritual traditions, and disasters in collective societies. J Psychol Theol 39(3):244-254

Dutton JE, Worline MC, Frost PJ, Lilius J (2006) Explaining compassion organizing. Adm Sci Q 51(1):59-96

Ehrenreich JH, Elliott TL (2004) Peace and conflict. J Peace Psychol 10(1):53-66

Ericson T, Kjønstad BG, Barstad A (2014) Mindfulness and sustainability. Ecol Econ 104:73-79

Eriksen C, Ditrich T (2015) The relevance of mindfulness practice for trauma-exposed disaster researchers. Emot Space Soc 17:63-69

Esbjörn-Hargens S, Zimmermann ME (2009) Integral ecology-uniting multiple perspectives on the natural world. Integral Books, Boston

Fehr R, Chi Yam K, Dang C (2014) Moralized leadership: the construction and consequences of ethical leader perceptions. Acad Manag Rev 40(2):182-209

Fernando M (2007) Corporate social responsibility in the wake of the Asian tsunami: a comparative case study of two Sri Lankan companies. Eur Manag J 25:1-10

Fesler JW (1965) The bureaucratic phenomenon. Adm Sci Q 10(2):261-266

Frawley D (2006) Yoga and the sacred fire: self-realization and planetary transformation. Motilal Banarsidass, Delhi

Gibson T, Wisner B (2016) 'Lets talk about you...'-opening space for local experience, action and learning in disaster risk reduction. Disaster Prev Manag Int J 25(5):664-684

Gidley J (2007) The evolution of consciousness as a planetary imperative: an integration of integral views. Integral Rev 5:4-226

Gifford R (2011) The dragons of inaction: psychological barriers that limit climate change mitigation and adaptation. Am Psychol 66:290-302

Glaser BG, Strauss AL (1967) The discovery of grounded theory: strategies for qualitative research. Aldine de Gruyter, New York 
Goleman D (1998) What makes a Leader? Harvard Bus Rev 76(6):93-102

Goleman D (2009) Ecological intelligence: how knowing the hidden impacts of what we buy can change everything. Doubleday, New York

Goleman D (2011) The Brain and Emotional Intelligence: New Insights. More than Sound, USA. http://www.mindful.org/danielgoleman-new-insights-on-emotional-intelligence/. Accessed 21 May 2017

Gonzalez T (2017) Root to rise: mindful lawyering for social justice. N Y Univ Rev law Soc Change 41:91-120

Greenberg MT, Harris AR (2012) Nurturing mindfulness in children and youth: current state of research. Child Dev Perspect $6(2): 161-166$

Greenwood D (2013) A critical theory of place-conscious education. In: Stevenson R, Brody M, Dillon J, Wals AJ (eds) International handbook of research on environmental education. Routledge, New York, pp 93-100

Gugerli-Dolder B, Frischknecht-Tobler U (eds) (2011) Umweltbildung Plus. Impulse zur Bildung für nachhaltige Entwicklung. Verlag Pestalozzianum, Zürich

Hall M, Lund E, Rummukainen M (2015) Klimatsäkrat Skåne. Centrum för miljö- och klimatforskning, Lunds universitet, Lund, Sweden

Hamilton M (2008) Integral city: evolutionary intelligences for the human hive. New Society Publisher, Gabriola Island

Hanh TN, Weisman A (2008) The world we have: a Buddhist approach to peace and ecology. Parallax Press, Berkeley

Hanley AW, Peterson GW, Canto AI, Garland EL (2015) The relationship between mindfulness and posttraumatic growth with respect to contemplative practice engagement. Mindfulness 6(3):654-662

Harvey A (2009) The hope: a guide to sacred activism. Hay House, USA

Hechanova RM, Ramos PAP, Waelde L (2015) Group-based mindfulness-informed psychological first aid after Typhoon Haiyan. Disaster Prev Manag Int J 24(5):610-618

Henslee AM, Coffey SF, Schumacher JA, Tracy M, Norris FH, Galea S (2015) Religious coping and psychological and behavioral adjustment after Hurricane Katrina. J Psychol 149(6):630-642

Hick SF, Furlotte CR (2009) Mindfulness and social justice approaches: bridging the mind and the society in social work practice. Canadian Social Work Review/Revue canadienne de service social 26(1):5-24

Hochwarter W, Laird M, Brouer R (2008) Board up the windows: the interactive effects of hurricane-induced job stress and perceived resources on work outcomes. J Manag 34:263-269

Hoeberichts JH (2012) Teaching council in Sri Lanka: a post disaster, culturally sensitive and spiritual model of group process. J Relig Health 51(2):390-401

Howard SJ (2016) Mindfulness may have risks as well as benefits. J R Soc Med 109(7):259-260

Howell AJ, Dopko RL, Passmore HA, Buro K (2011) Nature connectedness: associations with well-being and mindfulness. Personal Indiv Diff 51:166-171

Howell AJ, Passmore HA, Buro K (2013) Meaning in nature: meaning in life as a mediator of the relationship between nature connectedness and well-being. J Happiness Stud 14:1681-1696

Hülsheger UR, Alberts HJ, Feingold A, Lang JW (2013) Benefits of mindfulness at work: the role of mindfulness in emotion regulation, emotional exhaustion, and job satisfaction. J Appl Psychol 98(2):310

Hytten K, Hasle A (1989) Fire fighters: a study of stress and coping. Acta Psychiatr Scand Suppl 355:50-55
IFRC (2011) The sphere project: humanitarian charter and minimum standards in humanitarian response. $2011 \mathrm{edn} . \mathrm{http}: / / \mathrm{www}$. ennonline.net/fex/41/edition

Inayatullah S (2005) Spirituality and the future bottom line? Futures 27(6):573-579

Inayatullah S (2011) City futures in transformation: emerging issues and case studies. Futures 43:654-661

Inglis J (2008) How then do we choose to live? Facing the climate crisis and seeking "the meta response". Integral Rev 4(1):100-107

IPCC (Intergovernmental Panel on Climate Change) (2001) Third assessment report (TAR). Cambridge University Press, Cambridge

IPCC (Intergovernmental Panel on Climate Change) (2014) Climate change 2014: impacts, adaptation, and vulnerability. Cambridge University Press, Cambridge

Irving J, Dobkin P, Park J (2009) Cultivating mindfulness in health care professionals: a review of empirical studies of mindfulness-based stress reduction (MBSR). Complement Ther Clin Pract 15:61-66

Jacob J, Jovic E, Brinkerhoff MB (2009) Personal and planetary wellbeing: mindfulness meditation, pro-environmental behavior and personal quality of life in a survey from the social justice and ecological sustainability movement. Soc Indic Res 93(2):275-294

Jacobson JM (2008) Compassion fatigue, compassion satisfaction, and burnout: reactions among employee assistance professionals providing workplace crisis intervention and disaster management services. J Workplace Behav Health 21:133-152

Kabat-Zinn J (1990) Full catastrophe living: using the wisdom of your body and mind to face stress, pain and illness. Delacourt, NewYork

Kapucu N, Van Wart M (2008) Making matters worse: an anatomy of leadership failures in managing catastrophic events. Adm Soc 40:711-740

Kates RW, Clark WC, Corell R, Hall JM, Jaeger CC, Lowe I, McCarthy JJ, Schellnhuber HJ, Bolin B, Dickson NM, Faucheux S, Gallopin GC, Grübler A, Huntley B, Jäger J, Jodha NS, Kasperson RE, Mabogunje A, Matson P, Mooney H, Moore B 3rd, O'Riordan T, Svedin U (2001) Sustainability science. Sci New Ser 292(5517):641-642

Kaza S (2008) Mindfully green. Shambhala Publications, Boulder

Kim SH, Schneider SM, Kravitz L, Mermier C, Burge MR (2013) Mind-body practices for posttraumatic stress disorder. J Investig Med 61(5):827-834

Knodel M (2012) Mindfulness. Yale School of Forestry and Environmental Studies. Yale University, US. https://environment.yale. edu/blog/2012/10/mindfulness/. Accessed 01 May 2017

Knodel M (2014) Conceptualizing climate justice iIn Kivalina. Seattle UL Rev 37:1179

Koger SM (2015) A burgeoning ecopsychological recovery movement. Ecopsychology 7(4):245-250

Kunze I (2012) Social innovations for communal and ecological living. Lessons from sustainability research and observations in intentional communities. Communal Soc 32(1):50-67

Lang D, Wiek A, Bergmann M, Stauffacher M, Martens P, Moll P, Swilling M, Thomas C (2012) Transdisciplinary research in sustainability science: practice, principles, and challenges. Sustain Sci 7:25

Langer EJ (1989) Minding matters: the consequences of mindlessnessmindfulness. Adv Exp Soc Psychol 22:137-173

Lengyel A (2015) Mindfulness and sustainability: utilizing the tourism context. J Sustain Dev 8(9):35-51

Levinthal D, Rerup C (2006) Crossing an apparent chasm: bridging mindful and less-mindful perspectives on organizational learning. Organ Sci 17:502-513

Levy BS, Patz JA (2015) Climate change, human rights, and social justice. Ann Glob Health 81:310-322 
Linlja J (2009) Utveckling av en svensk version av Five Facets of Mindfulness Questionnaire (FFMQ_SWE). Master thesis, Linköping University, Linköping, Sweden

Lilly J, Kavanaugh J, Zelbst P, Duffy J (2008) The impact of human resource practices on low income workers in the context of a natural disaster. J Behav Appl Manag 10(1):110-136

Lockhart H (2011) Spirituality and nature in the transformation to a more sustainable world: perspectives of South African change agents. Doctoral dissertation, Stellenbosch: Stellenbosch University

Lu H, Schuldt J (2016) Compassion for climate change victims and support for mitigation policy. J Environ Psychol 45:192-200

Lyles W (2015) Compassion building practices to improve hazard mitigation and climate adaptation planning. In: Conference paper, 2015 ACSP (Association of Collegiate Schools of Planning) conference, Houston

Malik A, Qin X, Smith SC (2010) Autonomous adaptation to climate change: a literature review. Institute for International Economic Policy, Working Paper Series. The George Washington University, Washington, DC

Markowitz EM, Shariff AF (2012) Climate change and moral judgement. Nat Clim Change 2(4):243-247

Markowitz EM, Slovic P, Västfjäll D, Hodges SD (2013) Compassion fade and the challenge of environmental conservation. Judgm Decis Mak 8(4):397-406

Marques J (2014) Leadership and mindful behaviour: action, wakefulness, and business. Palgrave McMillan, New York

Matanle P (2011) The great east japan earthquake, tsunami and nuclear meltdown: towards the (re)construction of a safe, sustainable, and compassionate society in Japan's shrinking regions. Local Environ 16(9):823-847

May DR, Chang YK, Shao R (2015) Does ethical membership matter? Moral identification and its organizational implications. J Appl Psychol 100(3):681-694

Mayer FS, Frantz CM (2004) The connectedness to nature scale: a measure of individuals' feeling in community with nature. $\mathbf{J}$ Environ Psychol 24:503-515

McGeehan KM (2012) Cultural and religious belief systems, tsunami recovery and disaster risk reduction in American Samoa in the aftermath of the September 29, 2009 tsunami. Master of arts in Psychology

Miller TL, Grimes MG, Mcmullen JS, Vogus TJ (2012) Venturing for others with heart and head: how compassion encourages social entrepreneurship. Acad Manag Rev 37(4):616-640

Moore A, Malinowski P (2009) Meditation, mindfulness and cognitive flexibility. Conscious Cognit 18(1):176-186

Moser SC (2008) More bad news: the risk of neglecting emotional responses to climate change information. In: Moser SC, Dilling L (eds) Creating a climate for change: communicating climate change and facilitating social change. Cambridge University Press, Cambridge, UK, pp 64-80

Mueller MP, Greenwood DA (2015) Ecological mindfulness and crosshybrid learning: a special issue. Cult Sci Edu 10(1):1-4

O'Brien K, Hochachka G (2011) Integral adaptation to climate change. J Integr Theory Pract 5:89-102

O'Neill S, Nicholson-Cole S (2009) “Fear Won't Do It" promoting positive engagement with climate change through visual and iconic representations. Sci Commun 30(3):355-379

Osborne N, Grant-Smith D (2015) Supporting mindful planners in a mindless system: limitations to the emotional turn in planning practice. Town Plan Rev 86(6):677-698

Özpolat K, Rilling J, Altay N, Chavez E (2015) Engaging donors in smart compassion: USAID CIDI's greatest good donation calculator. J Hum Logist Supply Chain Manag 5(1):95-112

Paté-Cornell E, Cox LA (2014) Improving risk management: from lame excuses to principled practice. Risk Anal 34(7):1228-1239
Pfattheicher S, Sassenrath C, Schindler S (2016) Feelings for the suffering of others and the environment: compassion fosters proenvironmental tendencies. Environ Behav 48(7):929-945

Pio E, Syed J (2014) Sacred activism through seva and khidmat: contextualising management and organisations in South Asia. J Manag Organ 20(5):572-586

Purser R, Loy D (2013) Beyond McMindfulness. Blog. http://www.huffingtonpost.com/ron-purser/beyondmcmindfulness_b_3519289.html. Accessed 21 May 2017

Raab K (2014) Mindfulness, self-compassion, and empathy among health care professionals: a review of the literature. J Health Care Chaplain 20(3):95-108

Raab K, Sogge K, Parker N, Flament MF (2015) Mindfulness-based stress reduction and self-compassion among mental healthcare professionals: a pilot study. Ment Health Relig Cult 18(6):503-512

Ray PH, Anderson SR (2000) The cultural creatives: how 50 million people are changing the world. Three River's Press, New York

Reser J, Bragg E (2013) An editorial note: climate change and ecopsychology in Australia 4(4):266-268

Roberto KA, Henderson TL, Kamo Y, McCann BR (2010) Challenges to older women's sense of self in the aftermath of Hurricane Katrina. Health Care Women Int 31:981-996

Roeser S (2012) Risk communication, public engagement, and climate change: a role for emotions. Risk Anal 32(6):1033-1040

Roszak T (1992) The voice of the earth: discovering the ecological ego. Trumpeter 9(1)

Roszak T, Gomes ME, Kanner AD (1995) Ecopsychology: restoring the Earth, healing the mind. Sierra Club Books, San Francisco

Rowe J (2017) Georges Bataille, Chögyam Trungpa, and radical transformation: theorizing the political value of mindfulness. In: Dayley G (ed) The arrow: a journal of wakeful society, culture and politics. Special issue on Contemplative empowerment and social change, vol 4(2), pp 47-69

Ryan K (2016) Incorporating emotional geography into climate change research: a case study in Londonderry, Vermont, USA. Emot Space Soc 19:5-12

Sameshima P, Greenwood DA (2015) Visioning the centre for place and sustainability studies through an embodied aesthetic wholeness. Cult Sci Edu 10(1):163-176

Sandercock L, Senbel M (2011) Spirituality, urban life and the urban professions. In: Beaumont J, Baker C (eds) Postsecular cities: religious space, theory and practice. Continuum, London, pp 86-103

SCCV (2007) SOU 2007:60 Sweden facing climate change-threats and opportunities. Swedish Commission on Climate and Vulnerability (SCCV), Stockholm

Scharmer O (2009/2016) Theory U: leading from the future as it emerges. Berrett-Koehler Publishers, San Francisco, USA

Schwartz JM (2011) Mindfulness and materialist paradigm: mindbrain interaction and the breakdown of the materialist paradigm. https://www.youtube.com/watch? $\mathrm{v}=\mathrm{Ff} 2 \mathrm{cnQ69LK8}$. Accessed 2 May 2016 (Linked to Schwartz JM, Gladding R (2011) You are not your brain. Avery, New York)

Schwartz JM, Stapp HP, Beauregard M (2005) Quantum physics in neuroscience and psychology: a neurophysical model of mind-brain interaction. Philos Trans R Soc Lond B Biol Sci 360(1458):1309-1327

Senghaas-Knobloch E (2012) When the concept of mindfulness 'travels' to the realm of politics: a new look on the global care crisis as a challenge for socially sustainable development. Organizational and political mindfulness as approaches to promote social sustainability. artec paper Nr. 183, artec Forschungszentrum Nachhaltigkeit, Universität Bremen

Senghaas-Knobloch E (2014) Mindfulness: a politically sensitizing concept, care and social sustainability as issues. In: Becke G 
(ed) Mindful change in times of permanent reorganization. CSR, sustainability, governance ethics. Springer, Berlin, pp 191-208

Setti I, Argentero P (2014) The role of mindfulness in protecting firefighters from psychosomatic malaise. Traumatol Int J 20(2):134

Setti I, Argentero P (2015) Well-being among volunteer firefighters: Mindfulness as psychological resource [Il benessere nei vigili del fuoco volontari: La mindfulness come risorsa psicologica]. Psicologia della Salute 2:101-121

Sharp J (2009) Geography and gender: what belongs to feminist geography? Emotion, power and change. Prog Hum Geogr 33(1):74-80

Shepherd DA, Williams TA (2014) Local venturing as compassion organizing in the aftermath of a natural disaster: the role of localness and community in reducing suffering. J Manag Stud 51(6):952-994

Sheth J, Sethia N, Srinivas S (2010) Mindful consumption: a customercentric approach to sustainability. J Acad Mark Sci 39(1):21-39

Shiyko MP, Hallinan S, Naito T (2017) Effects of mindfulness training on posttraumatic growth: a systematic review and meta-analysis. Mindfulness 8(4):848-858

Simpson AV, Clegg S, Pitsis T (2014a) Normal compassion: a framework for compassionate decision making. J Bus Ethics 119(4):473-491

Simpson AV, Clegg SR, Lopes MP, Cunha MP, Rego A, Pitsis T (2014b) Doing compassion or doing discipline? Power relations and the Magdalene Laundries. J Polit Power 7(2):253-274

Simpson AV, Cunha MPE, Clegg S (2015) Hybridity, sociomateriality and compassion: what happens when a river floods and a city's organizations respond? Scand J Manag 31(3):375-386

Siqueira R, Pitassi C (2016) Sustainability-oriented innovations: can mindfulness make a difference? J Clean Prod 139:1181-1190

Slovic P (1999) Trust, emotion, sex, politics, and science: surveying the risk-assessment battlefield. Risk Anal 19(4):689

Smith N, Leiserowitz A (2014) The role of emotion in global warming policy support and opposition. Risk Anal 34:937-948

Smith BW, Ortiz JA, Steffen LE, Tooley EM, Wiggins KT, Yeater EA, Montoya JD, Bernard ML (2011) Mindfulness is associated with fewer symptoms, depressive symptoms, physical symptoms, and alcohol problems in urban firefighters. J Consult Clin Psychol 79:5:613

Sol J, Wals AEJ (2015) Strengthening ecological mindfulness through hybrid learning in vital coalitions. Cult Sci Edu 10(1):203-214

Srivatsa UN, Ekambaram V Jr, Saint Phard W, Cornsweet D (2013) The effects of a short term Stress Alleviating Intervention (SAI) on acute blood pressure responses following a natural disaster. Int J Cardiol 168(4):4483-4484

Strauss AL, Corbin J (1998) Basics of qualitative research. Techniques and procedures for developing grounded theory, 2nd edn. Sage, Thousand Oaks

Sumi A (2007) On several issues regarding efforts toward a sustainable society. Sustain Sci 2(1):67-76

Thomas D, Fox R, Miller C (2015) Voices from the field: Wildland fire managers and high-reliability organizing mindfulness. Soc Nat Resour 28(8):825-838

Thompson RW, Arnkoff DB, Glass CR (2011) Conceptualizing mindfulness and acceptance as components of psychological resilience to trauma. Trauma Violence Abuse 12(4):220-235

Udomratn P (2009) Mental health and the psychosocial consequences of natural disasters in. Asia Int Rev Psychiatry 20(5):441-444

Vandemark LM (2007) Promoting the sense of self, place, and belonging in displaced persons: the example of homelessness. Arch Psychiatr Nurs 21(5):241-248

Vogus TJ (2011) Mindful organizing: establishing and extending the foundations of highly reliable performance. In: Cameron K,
Spreitzer GM (eds) Handbook of positive organizational scholarship. Oxford University Press, Oxford, pp 664-676

Vogus TJ, Sutcliffe KM (2012) Organizational mindfulness and mindful organizing: a reconciliation and path forward. Acad Manag Learn Educ 11:722-735

Vogus TJ, Welbourne TM (2003) Structuring for high reliability: HR practices and mindful processes in reliability-seeking organizations. J Organ Behav 24:877-903

Waelde LC, Uddo M, Marquett R, Ropelato M, Freightman S, Pardo A, Salazar J (2008) A pilot study of meditation for mental health workers following Hurricane Katrina. J Trauma Stress 21(5):497-500

Walsh Z (2016) A meta-critique of mindfulness critiques: from McMindfulness to critical mindfulness. In: Purser R, Forbes D, Burke A (eds) Handbook of mindfulness: culture, context, and social engagement. Springer, Cham

Wamsler C (2014) Cities, disaster risk and adaptation. Routledge, Abingdon, Oxon, UK

Wamsler C, Brink E (2014a) Interfacing citizens' and institutions' practice and responsibilities for climate change adaptation. Urban Clim 7:64-91

Wamsler C, Brink E (2014b) Planning for climatic extremes and variability: a review of Swedish municipalities'. Adapt Responses Sustain 6:1359-1385

Wamsler C, Brink E (2018) Mindsets for sustainability: exploring the link between mindfulness and sustainable climate adaptation (forthcoming)

Wamsler C, Brossmann J, Hendersson H, Kristjandottir R, McDonald C, Scarampi P (2017) Mindfulness in sustainability science, practice, and teaching. Sustain Sci 1-20. https://doi.org/10.1007/ s11625-017-0428-2

Watkins MB, Ren R, Umphress EE, Boswell WR, del Carmen M, Zardkoohi A (2015) Compassion organizing: employees' satisfaction with corporate philanthropic disaster response and reduced job strain. J Occup Organ Psychol 88(2):436-458

Weick KE, Putnam T (2006) Organizing for mindfulness: Eastern wisdom and Western knowledge. J Manag Inq 15:275-287

Weick KE, Sutcliffe KM (2007) Managing the unexpected, 2nd edn. Wiley, San Francisco

Weick KE, Sutcliffe KM, Obstfeld D (1999) Organizing for high reliability. Res Organ Behav 21:81-123

Williams JMG, Kabat-Zinn J (2011) Mindfulness: diverse perspectives on its meaning, origins, and multiple applications at the intersection of science and dharma. Contemp Buddh 12(01):1-18

Wisner B (2015) Speaking truth to power: a personal account of activist political ecology. In: Perreault T, Bridge G, McCarthy J (eds) The Routledge Handbook of Political Ecology. Routledge, Abingdon, UK, pp 53-63

Woiwode C (2016) Off the beaten tracks: the neglected significance of interiority for sustainable urban development. Futures 84:82-97

Wood W, Mazur T (2016) Do no harm: mindful engagement for a world in crisis. 2 edn, RioKai Press, Mendocino, California, USA

Yeh TD-I (2006) The way to peace: a buddhist perspective. J Peace Stud 11(1):91-112

Yoshimura M, Kurokawa E, Noda T, Hineno K, Tanaka Y, Kawai Y, Dillbeck MC (2015) Disaster relief for the Japanese earthquaketsunami of 2011: stress reduction through the transcendental meditation technique 1, 2, 3. Psychol Rep 117(1):206-216

Zeller M, Yuval K, Nitzan-Assayag Y, Bernstein A (2015) Selfcompassion in recovery following potentially traumatic stress: longitudinal study of at-risk youth. J Abnorm Child Psychol 43(4):645-653 